\title{
Discussing Corporate Ecological Accounting and the Realistic Choice for China
}

\author{
Yan Xiao \\ Central South University of Forestry and Technology, Changsha 410004, Hunan, China \\ Guilin University of Technology, Guilin 541004, Guangxi, China \\ E-mail: xy6332@163.com \\ Xiaoxiao Que \\ Guilin University of Technology, Guilin 541004, Guangxi, China \\ E-mail:289992870@qq.com
}

\begin{abstract}
As the global attention being paid on ecological environment, the ecological accounting can provide environmental information by its unique methods. The introduction of the ecological accounting is not only the need of sustainable development of economy but also for enterprise's long-term competitiveness. From the background of ecological accounting, this paper describes the research content of ecological accounting, and make analysis of its present situation and problems, the necessity of building Chinese corporate ecological accounting and principle are discussing.
\end{abstract}

Keywords: Ecological accounting, Present situation and problems, Realistic choice

\section{Edeological foundation and social background}

\subsection{Severe environmental problems}

The heavy damage to our planet's natural resources not only affect society's ability to carry out sustainable development, moreover it poses numerous negative health threats to the population. Facing the stern environment question, many countries are forced to ask themselves the degree they value their natural environment, as the situation becomes ever more dire, more research is desperately needed to reverse this trend. The sustainable development theory currently proposed reflect the need for people to adapt to the sustainable development request information system as best reflect the economical, social, and the ecology operational improvement ideologies. Whilst the strategy prove difficult to implement, the positive benefit is that it constitutes the driving force for the need for ecological accounting.

\subsection{A change of perspective on corporate social responsibility}

In western society, the people divide corporate social responsibility into two stages: firstly, under the free and open competition the idea was the maximum of enterprise value in the19th century; Second, in the 1950s the later modern corporate social responsibility, namely that the corporate social responsibility is not only to achieve maximum profit, but simultaneously should contribute to the good of society. Under the modern corporate social responsibility view's influence, in the early $70 \mathrm{~s}$ when the western nations introduced the notion of social responsibility accounting, the issue of environmental responsibility was a very important component. Along with the environmental protection laws and regulations' perfection, the measurement, the report, the management of enterprise's effect in environment had already become one of enterprise's successful management prerequisites. Therefore from the view point of an interested party, we can observe that the shareholder pay more and more attention on environmental information.

\subsection{Ecological accounting on the basis of circulation economy and ecological economy}

Circulation economy and ecological economy are new development views, which are the result of reasonable utilization of natural resources and environment optimization, the result of the understanding of the relationship between society and nature, the result of the deep reflection on environmental and resource crisis. In order to make economic growth and economic benefit, ecological environment work harmoniously and unified, need to have a research of ecological environment, the need to record the value of human society and the exchange of material, energy and information system. For example the environmental statistics, calculating green GDP of information system. As this kind of information system of ecological accounting has a representative of the 
important value of accounting, it can reflect the behavior of the enterprise environment control and ecological effects.

\section{The chief content of ecological accounting}

Ecological accounting which separated from financial accounting is the product of the finance accounting when it develops to a certain stage. In embryonic stage of ecological accounting, some with ecological characteristic of accounting is adjusting the relevant items in the financial and accounting statements to reflect the cost incurred. When observing a higher sense of environmental protection consciousness, the government and the people from all walks of life want to have a deeper understanding of the influence of enterprise's economic activities on the natural environment. Therefore ecological accounting gradually form relatively independent theoretical system and method. It is a new concept today, which incorporates sociology, environmental science and accounting, and it belongs to the present accounting system or additional subsystem. In order to adjust to the human sustainable development strategy, ecological accounting makes the system of accounting systems and control of enterprise environmental influence own new functions.

In the accounting system and control of enterprise's of environmental impact assessment, the first problem encountered is the collection of ecological accounting data, namely to physical units of data collection, such as the matter and energy from the business process of enterprise and the effect on the absorption and emission ecological environment of matter and energy. The environmental impact of the provided data during this stage can form social ecology accounting and then report to the public. For the convenience of users to understand, we need to process this ecological information since the present accounting system is measured by currency information, and to do that you need to change some physical unit for ecological information into currency information, the monetary index developed assigns each accounting subject, like the ecology property, the ecology debt, the ecology cost and the ecological benefit, cause the information user to be possible direct-viewing to see the ecological benefit the situation.

Foreign scholar Frank Ken thinks that ecological accounting provides area manager or the organization performance evaluation and control, decision-making and reports the needed information, it is also based on ecological and economic two areas of concept, unit of measurement and value. Based on related literature study, ecological accounting usually includes the following content:

First, ecological and economic decision-making. When Enterprises are making economic decision for some project which related to ecological environment, scientific forecast should be made according to the need of environment protection and ecological benefit. In order to achieve the ecological benefit, the decision analysis method can be got from management accounting and some new methods that considered ecological accounting characteristics.

Second, the ecological economy, and its control budget. Upon completing the ecological economic decision-making and related solutions, choose the ecological accounting practice should be subjected to the management accounting and formulated corresponding budget. The budget generally belongs to the special budget for decision making. To ensure the smooth implementation of the budget, the accounting department should strengthen the control and supervision, find out the weak link and correct deviation.

Third, performance evaluation. In the final, analysis the ecological economy accounting the budget implementation and results and summing up experience, lessons, and the relevant responsible unit and individual shall reward.

Fourth, disclosure of accounting. In the final, give a relevant report about enterprise accounting process of ecological economic activity, compiled to reveal the information users.

\section{Present situation and problems}

\subsection{Present situation}

Environmental problems are not only a technical problem, but also an economic issue, environmental disclosure requirements, promotes the development of the ecological accounting research. In the United States, Europe and other countries, through the implementation of environmental laws and regulations, establishes the ecological accounting as a influential new field of accounting, and are reproduced quickly as many companies must be submitted to the regulatory inspection report. Such as the United States was established in 1989, and discharge poisonous substances required number of all full-time employees more than 10 companies listed among the report material discharged, Denmark's environmental protection act chapter requirement of the enterprise business disclosure environmental impact, Britain's biggest encourage domestic enterprises provide 350 
information of greenhouse gas emissions, In 2000, Australia also started compulsory enterprise report for reducing emissions of pollutants. More and more developing countries begin to promulgate environmental laws and regulations. China has promulgated the "environmental protection", "the water pollution prevention". etc, to strengthen the protection of the ecological environment. The Kyoto protocol on "pollution-discharge right trade" and greenhouse gas emissions are calculated, the strict rules that enterprises in environmental pollutants in the information disclosure by enough attention. For regulators offer enterprise correct pollutants information, ecological accounting plays a key control and track function, mainly through the environmental intervention, the material flow, ecological impact assessment physical measurement method to measure and control environmental behavior.

\subsection{The facing problems}

It is no surprise the implementation of ecological accounting will encounter some problems, its core is the environmental externalities, externality can be useful (external economy), also can be unfavorable (external diseconomy). For environmental problems, external diseconomy performance is very obvious. When each enterprise can be arbitrary, free and unrestricted common resources exploitation, they can be from the resources exploitation, and gain is benefit there from. In the profit motive, driven by the decision of different levels in production, investment and consumption activities, they often only from their own angle to consider all sorts of selection of the cost and benefits, regardless of social consequences arising there from. Many enterprises to jointly develop the resources of pollution free, the result does not undertake any responsibility, will inevitably lead to the exhaustion of the resources, causing serious pollution and resource shortages. The ecological environment of enterprise accounting provides the ecological behavior driver, but the externalities retard the building enthusiasm in ecological protection. Therefore, waiting for the enterprise accounting system of ecological spontaneously is very difficult. Upon reflection of ecological accounting supervision and enterprise's impact on the environment, we can establish that no managers, shareholders want their company to develop a poor reputation. In order to maintain a good public image, they may provide false information, thus if we want to strengthen the ability of ecological accounting, we first need to strengthen the auditory capabilities of third parties. Second is the physical environment and currency information into information; with the traditional accounting, ecological accounting is the main task of the data classification, collect, record, distribution, analysis, and transfer, but we still cannot rely on environmental economics, and so will all enterprise environmental impact of using monetary indicator.

\section{Realistic choice of China}

\subsection{The necessity of introducing ecological accounting}

Since the current ecological and environmental problems become increasingly prominent, creation the ecological accounting which will provide decision support for Chinese enterprises to sustainable development and utilization of natural resources and protect the natural environment. They need to be praised as they gain competitive advantage in sustainable investments and achieves the corporate goals of sustainable development is particularly important, specific improvement in the following areas:

\subsubsection{Required by Sustainable development strategy}

As China has always being a heavy user of all natural resources in their production process, not only oil, minerals and other non-renewable natural resources depletion, but also water, forest and other renewable resources are being over-exploitation, thus natural resources are being irreparably damaged and the quality of environmental resources have rapidly declined. When the depletion of natural resources and deterioration of ecological resources have reached a certain extent, is bound to affect sustainable development and human survival. Ecological accounting is the information tools to solve environmental problems and achieve sustainable human development. It is very important to change economic growth mode from extensive to sustainable one, eliminate and avoid the consequences of manufacturing industry development impact on the ecological and environmental and implement comprehensive, coordinated and sustainable scientific development concept.

\subsubsection{Required by enterprises to obtain long-term competitiveness}

If companies want to remain invincible in the market, they must have a clear competitive advantage. With the people's enhanced awareness of ecological and environmental protection, such as the governments give the corporation who have good environmental performance many preferential policies and support, the majority of consumers are starting to advocate green consumption. The competitiveness of enterprises are not only the competition of product cost, product quality, commodity prices, market share and service quality, ecological and environmental protection awareness, the merits of ecology efficiency are becoming an important part of 
obtaining a competitive advantage. Who has the advantage of ecological environmental protection, who will be able to get more government support such as tax concessions and so on, which could achieve some cost advantages; green consumption concept of adoption may be made of such enterprises has more market share. Therefore, the introduction of ecological accounting will encourage Chinese enterprises to take the initiatives in the program and help seize the lead position in the market. New competitive advantage is reflected in the green corporate image, clean production, processing and reusing the used product and so on a series of environment-friendly measures which protect environment and effective use of resources, making business activities to minimize environmental impact. From a forward-looking perspective, the introduction of ecology accounting is necessary to integrate a long-term competitive advantage strategy with enterprise management innovation for Chinese enterprises.

\subsubsection{Required by information demanders}

China's ecology accounting information demander, can be broadly classified into three categories: government, economic stakeholders and the environment. Government is the environmental policy implementer, who carry out all work requires different ecology accounting informations, therefore, the government is an important ecology accounting demander. As the impact on the environment has become the necessary elements to be considered when operating an enterprise, the traditional economic stakeholders who want to maintain their own economic interests, will pay more attention to corporate environmental information; employees, consumers and others individuals affected by enterprise environment practices, with a stronger environmental awareness, they hope to clear the impact of their own health benefits by ecology accounting information

\subsection{Principle thinking for establishing China ecological accounting}

Chinese accounting systems need ecology accounting, however at current stage to create China ecology accounting, the following principles may be necessary:

First, using the gradual improvement principle. The implementation of environmental accounting research in China started relatively late, there are a lot of difficulties and shortage, the research on the ecology accounting is still in its infancy, therefore, it is unrealistic to expect sudden improvements of ecology accounting to a high level and should gradually improve in strategy.

Second, policy principle. At present, Chinese enterprises lack the internal motivation and external pressure when implement ecological accounting. This requires that we must not only to increase standards and systems for ecological accounting, also have to improve and perfect various environmental regulations and introduce a series of policies and measures to Stimulate, guide enterprises to focus on environmental management and environmental accounting.

Third, coexistence of a variety of measurement principle. Ecological accounting not only to use money measurement as a measurement standard, but also extensive use of physical measurements and other measurements as measurement standards; not only to reveal quantitative, but also to reveal qualitative in a wide range. To roundly, integrated reflect enterprises' ecological and economic activities and results and provide the information required by information users.

\section{References}

Geng Jianxin \& Cao Guangliang. (2007). Concerning concept of green accounting. Finance and Accounting Monthly (accounting), (2)

Hao Xiaoyan. (2006). Rediscovery of "green accounting" based on circular economy. Technological Economy, (5)

Qin Yan \& Huang Lijun. (2007). Shallow enterprise's external green accounting. Management of China's environment, (3)

Wang Zhongjian \& Li Mushan. (2007). Several ideas about green accounting. China Collective Economy, (6)

Xu Jialin \& Cai Chuanli. (2004). Retrospect and prospect of China's environmental accounting research. Accounting Research, (4)

Yang Zongchang \& Zhong Ziliang. (2002). About the idea of green accounting. Sichuan Accounting, (7)

Yu Xuelian. (2005). The new trend of development of financial accounting under circular economy. Financial Forum, (2)

Zhang Xiuyun, Xu Jingxin, Zhang Xufang \& Gao Qingfang. (2008). About the idea of implementing green accounting in China. The window of the reform, (5). 